\title{
ESBOÇO DE UM MODELO DE VALORIZAÇÃO TURÍSTICA PARA A REGIÃO FRONTEIRIÇA DO DOURO/DUERO
}

\author{
João Pedro Almeida Mendonça \\ Instituto Superior da Maia - ISMAI \\ CEDTUR - Centro de Estudos de Desenvolvimento Turístico; CETRAD \\ mendonca.u@gmail.com
}

\begin{abstract}
Resumo: Dentro da grande diversidade de programas de desenvolvimento regional, promovidos pela União Europeia, estão contemplados os projetos de cooperação e de ordenamento do território de carácter transnacional. Tal como a generalidade da política europeia de base regional, pretendem combater as desigualdades nos padrões de qualidade de vida entre as áreas mais desenvolvidas da Comunidade e aquelas que se situam em territórios social ou economicamente mais débeis.A região fronteiriça definida pelo rio Douro, no seu troço internacional (português e castelhano-leonês) acumula uma série dessas particularidades. Propomo-nos nesta comunicação abordar, numa perspetiva eminentemente geográfica, quais os elementos de carácter material e imaterial a considerar num processo de valorização turística, assente na cooperação entre Portugal e Espanha.
\end{abstract}

Palavras-chave: Douro Internacional, cooperação, turismo

\begin{abstract}
Draft of a model of tourism recovery for border region Douro/Duero
Within the great diversity of regional development programs promoted by the European Union are the cooperation projects and the transnational planning. As the majority of European regional politics, they intendto tackleinequalitiesin standards of living between the more developed areas of the Community and those situated in weaker areas,socially and economically. The border region defined by the River Douro in its international section (Portuguese and Castilian-Leonese) accumulates a number of these peculiarities. We propose to address in this communication, an eminently geographical perspective, what elements of material and immaterial nature have to be considered in at tourist valorization process, based on cooperation between Portugal and Spain.
\end{abstract}

Keywords: International Douro; Cooperation; Tourism

Resumen: Esbozo de un modelo de revalorización turística para la región fronteriza del Duero

Dentro de la gran diversidad de programas de desarrollo regional promovidos por la Unión Europea se incluyen los proyectos de cooperación y de ordenación del territorio de carácter transnacional. Estos, como la mayor parte de las políticas europeas de base regional, preten- 
den hacer frente a las desigualdades en los estándares de calidad de vida entre las áreas más desarrolladas de la Comunidad y aquellas que se sitúan en territorios social o económicamente deprimidos. La región fronteriza definida por el río Duero acumula en su tramo internacional (portugués y castellano-leonés) una serie de esas peculiaridades. En esta comunicación nos proponemos abordar, desde una perspectiva eminentemente geográfica, cuáles son los elementos de carácter material e inmaterial que deben considerarse en un proceso de revalorización turística basado en la cooperación entre Portugal y España.

Palabras clave: Duero Internacional, cooperación, turismo

\section{O MARCO TEÓRICO}

Nos últimos anos assiste-se a uma reformulação das linhas de intervenção nas áreas rurais menos dinâmicas. Se é certo que, em geral, estes espaços perderam capacidade produtiva, povoação e mesmo influência decisória na hora de captar investimentos, nunca como hoje foram tão amplamente debatidos. É neste contexto que avaliar um território como o do vale do Douro, no seu marco territorial em que é possível uma articulação ao nível do planeamento entre os dois estados peninsulares, pode constituir uma perspetiva inovadora e pertinente, até porque, como é sabido, se atravessa na atualidade um período de contenção financeira e de obrigatória racionalização de recursos.

Por vezes, a simples manutenção de algumas atividades agrárias e serviços, ou pelo menos o surgimento de atividades complementares à agricultura, ainda que de pequena escala, podem constituir oportunidades de desenvolvimento para essas áreas, mantendo um nível de população mínimo que evite o decréscimo continuado e a completa desertificação humana. É neste contexto que surgiu este texto, em torno das paisagens e recursos territoriais do Douro.

\section{O TERRITÓRIO}

O rio Douro drena um território muito vasto da Península Ibérica: a maior parte da Comunidade de Castela-Leão (Espanha) e a região Norte de Portugal. O seu percurso, predominantemente de Este para Oeste, numa extensão de $927 \mathrm{Km}$, estrutura diferentes unidades territoriais. Em determinados troços trata-se de uma via navegável, em outros adopta a função de espaço de fronteira; às vezes está próximo de regiões urbanas dinâmicas, noutros casos serve áreas marcadamente periféricas e de cariz rural. Interessa no presente caso o troço correspondente ao território de fronteira. 
Figura 1. Mapa de localização do Douro/Duero

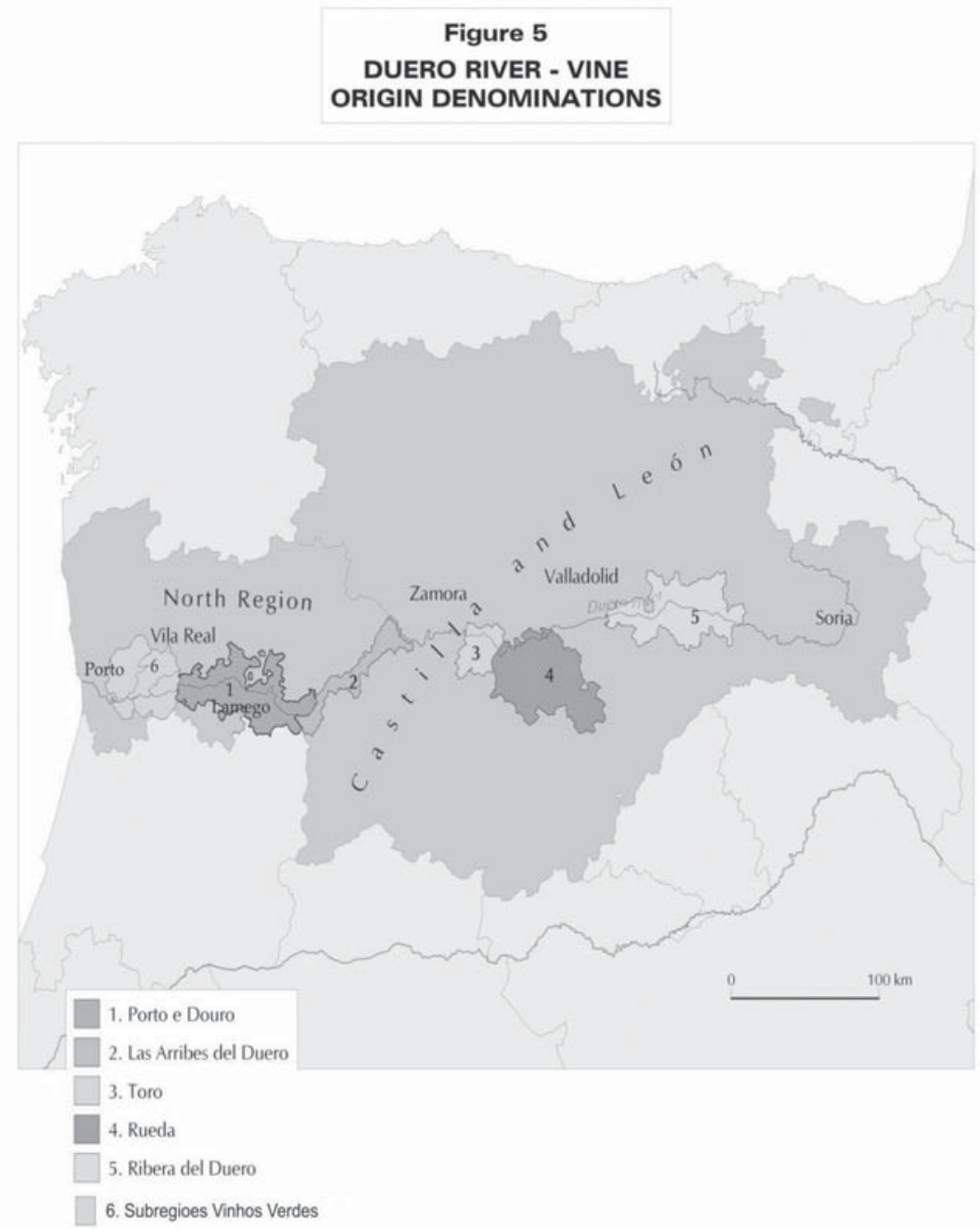

O Douro como espaço de fronteira coincide com as fragas e os entalhes graníticos. Até à região fronteiriça correspondente ao Douro internacional, o rio percorre mansamente as manchas argilosas da meseta em cerca de $600 \mathrm{~km}$, mas a partir daí, num troço de $122 \mathrm{~km}$ até Barca de Alva, uma sucessão de fortes desníveis, hoje regularizados pela construção das represas, tornam a paisagem muito mais agreste. O contraste chega a ser quase inesperado. Num abrir e piscar de olhos o rio desaparece por entre os quartzitos e granitos, formando imponentes muros de rocha que o aprisionam. Nesse troço, o rio passa, de uma forma bastante abrupta, dos 700 metros de cota para os 150 metros. 
Figura 2. Escarpas do Douro Internacional

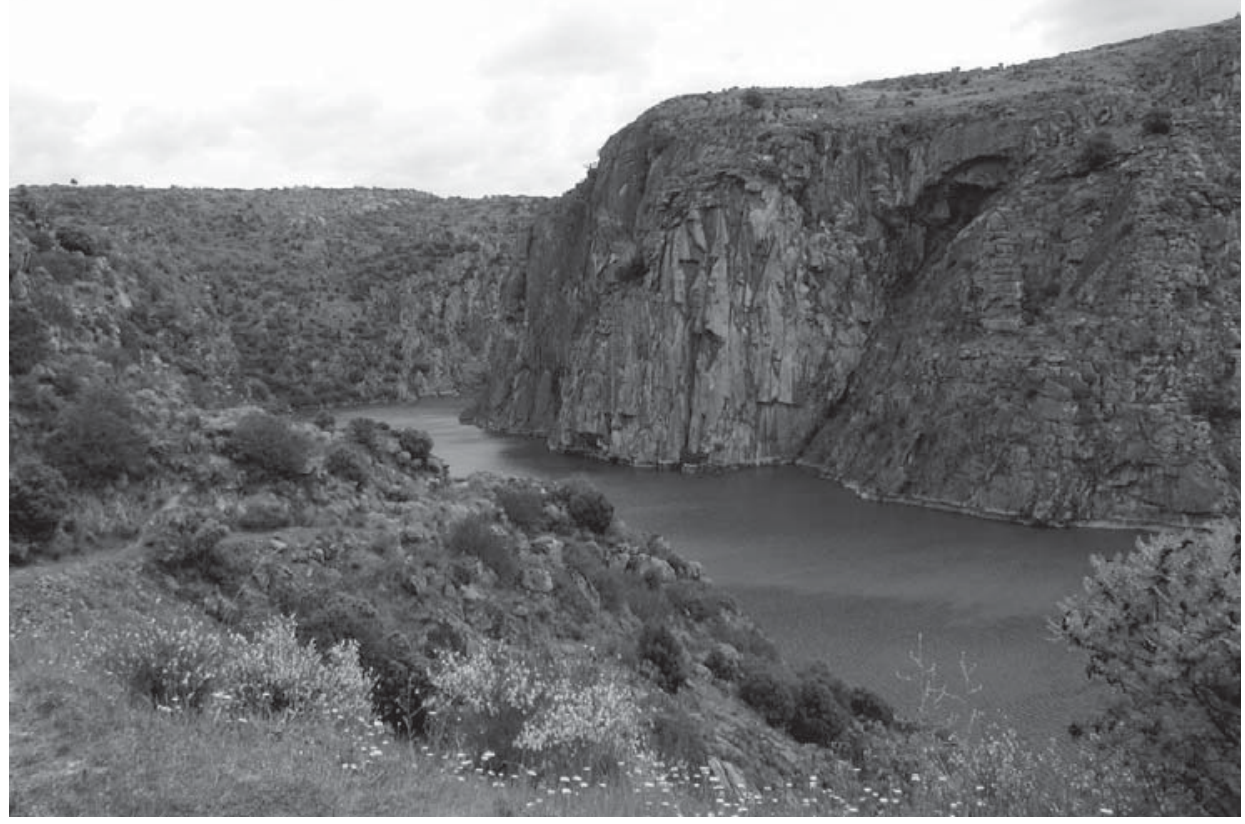

A aridez e rudeza da paisagem resultam igualmente de uma gradação climática. Os baixos índices pluviométricos conferem ao clima características marcadamente mediterrâneas, atingindo-se valores de precipitação anual semelhantes aos que se verificam no interior alentejano ou no Algarve (da ordem dos 400 a $500 \mathrm{~mm}$ de precipitação, em média, ao longo do ano, chegando mesmo a valores inferiores a $400 \mathrm{~mm}$ em determinados locais mais abrigados). Para encontrarmos índices de aridez um pouco mais ténues, com Invernos mais frios e não tão secos, semelhantes ao interior Castelhano-Leonês, temos de nos afastar das zonas mais abrigadas dos vales e de nos aproximar das serranias vizinhas.

A flora e em alguns casos a própria toponímia permitem distinguir esses dois grandes conjuntos paisagísticos. Por um lado a flora específica onde imperam os frutos secos e determinados grupos florísticos típicos do Mediterrâneo, sendo de destacar bosques de zimbros ("Juniperusoxycedrus") e manchas descontínuas de quercíneasperenifólias: azinheiras ("Quercus rotundifolia”) e sobreiros ("Quercus suber"). Na parte planáltica, a influência mais continental dá lugar a uma menor presença dos cultivos permanentes que são predominantes no vale, surgindo pequenas manchas de carvalhos negrais ("Quercus pyrenaica") e uma maior representatividade dos pastos naturais para gado e de terrenos aráveis para a cerealicultura, assim como pequenas extensões de vinha, maioritariamente para autoconsumo. No lado português surge a Indicação de Proveniência Regulamentada "Planalto Mirandês", do lado espanhol a Indicação "Arribes". 
Figura 3 - Vinhas das "Arribes"

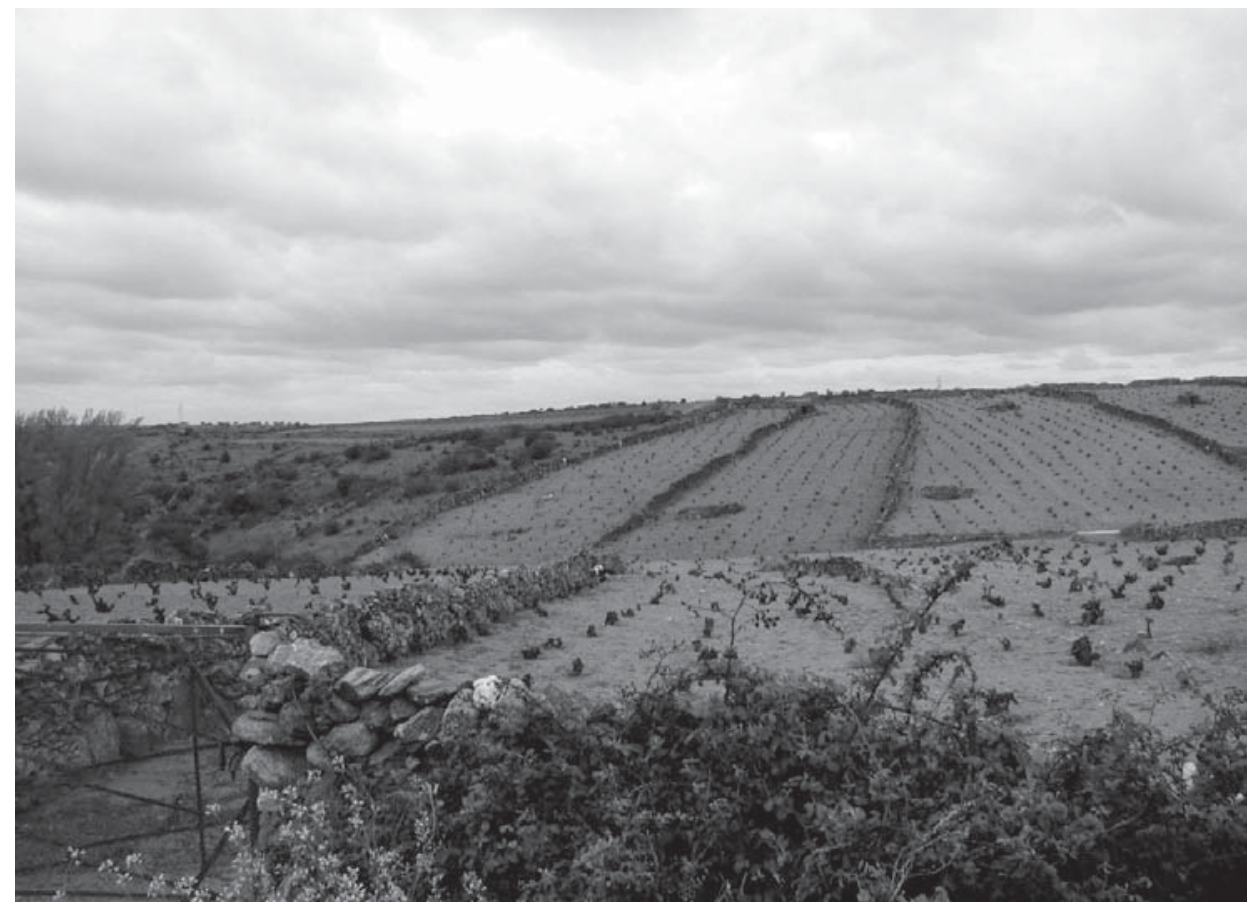

Uma das iniciativas mais recentes de nível territorial veio reconhecer o particular valor ambiental do troço internacional do Rio Douro, local de nidificação de numerosas espécies da avifauna (Zona Especial de Protecção de Aves - o Grifo (“Gypsfulvus”), a cegonha negra ("Ciconianigra”), a águia de Bonelli ("Hieraaetusfasciatus")) e igualmente local de refúgio para espécies de animais em risco, nomeadamente o lobo ("Canis lupus") e o gato-bravo (Félix silvestris”). Esta área está incluída em dois Parques Naturais: Parque do Douro Internacional, no caso de Portugal, Parque das Arribas do Douro, no caso de Espanha.

Uma das melhores perspetivas do Douro Internacional consiste na viagem de barco entre a praia da Congida, em Freixo-de-Espada-a-Cinta e a barragem de Aldeiadávila. A paisagem destaca-se pela sua imponência. Enormes blocos graníticos em tons de cinza alternam com pequenos tufos arbustivos e o colorido de algumas árvores dispersas, suspensas sobre os abismos. Poder-se-ia depreender desta nossa descrição que existe uma certa uniformidade paisagística, mas isso é apenas associável a uma visão ampla do território. A natureza é pródiga em surpresas. Variando com o declive, com o tipo de rocha e com a disposição das diáclases, diferentes coloridos e tonalidades fazem variar o padrão dominante. Em alguns locais, o recuo abrupto das vertentes impede a presença da vegetação, assumindo o granito ou os quartzitos as suas cambiantes que vão do castanho - avermelhado ao cinza claro, passando também por tonalidades amareladas. Quando existe a vegetação, esta pode ser contínua, em manchas mais ou menos amplas, em regra 
na proximidade do rio, aproveitando a maior presença da humidade, ou em locais onde a topografia é mais benigna. Nos topos, sempre que estes são aplanados, vislumbram-se manchas arbóreas de carácter mais uniforme e por vezes cultivos humanos, incluindo-se neste caso a já citada vinha, os olivais ou ainda pomares frutícolas.

Falar da região vinhateira do Douro é evocar um dos territórios de maior singularidade de Portugal. HermannLautensach considera-a mesmo uma das regiões naturais do Portugal interior, pela oposição nítida, entre o vale do Douro e os planaltos de Trásos-Montes e Beira Transmontana, a montante da freguesia de Barqueiros (concelho de Mesão Frio). Esse contraste resulta não apenas da orografia revolta, que se traduz em profundos entalhes do rio Douro e dos seus afluentes principais, mas igualmente por possuir uma geologia distinta da que existe nas áreas vizinhas. $\mathrm{O}$ vale do Douro vinhateiro é predominantemente constituído por xistos e grauvaques, Pré-Câmbricos e Câmbricos. No prolongamento dos vales fluviais secundários, já fora da região vitícola, existem maioritariamente afloramentos plutónicos (granitos), do ciclo orogénico Hercínico. Ocorre portanto uma quase perfeita coincidência entre a vinha e o subsolo de xisto, em nítido contraste com as rochas dominantes nos relevos que a circundam. A parte portuguesa do Douro Internacional não difere em muito desta descrição mais ampla do território vinhateiro.

O predomínio de xistos confere à paisagem uma característica particular, que alguns autores comparam a um "mar de cabeços" e no dizer de Orlando Ribeiro, «topografia a um tempo confusa e monótona, que tem sido comparada, expressivamente, a montículos de toupeiras ou às tendas de um imenso acampamento de nómadas.» (Daveau et al., 1987: 174) Rocha muito mais impermeável do que o granito, é essencialmente sujeita a um desgaste de superfície que parte a rocha e a esfolia. Em regra, a rede hidrográfica adquire grande densidade, os vales são relativamente apertados, mas, ao contrário do modelado granítico, onde o recuo das vertentes se faz de forma por vezes abrupta, com escarpas vivas e de ângulos bem marcados na base, no xisto todas as vertentes e superfícies se alteram de forma progressiva e por um todo. 
Figura 4- Barca de Alva

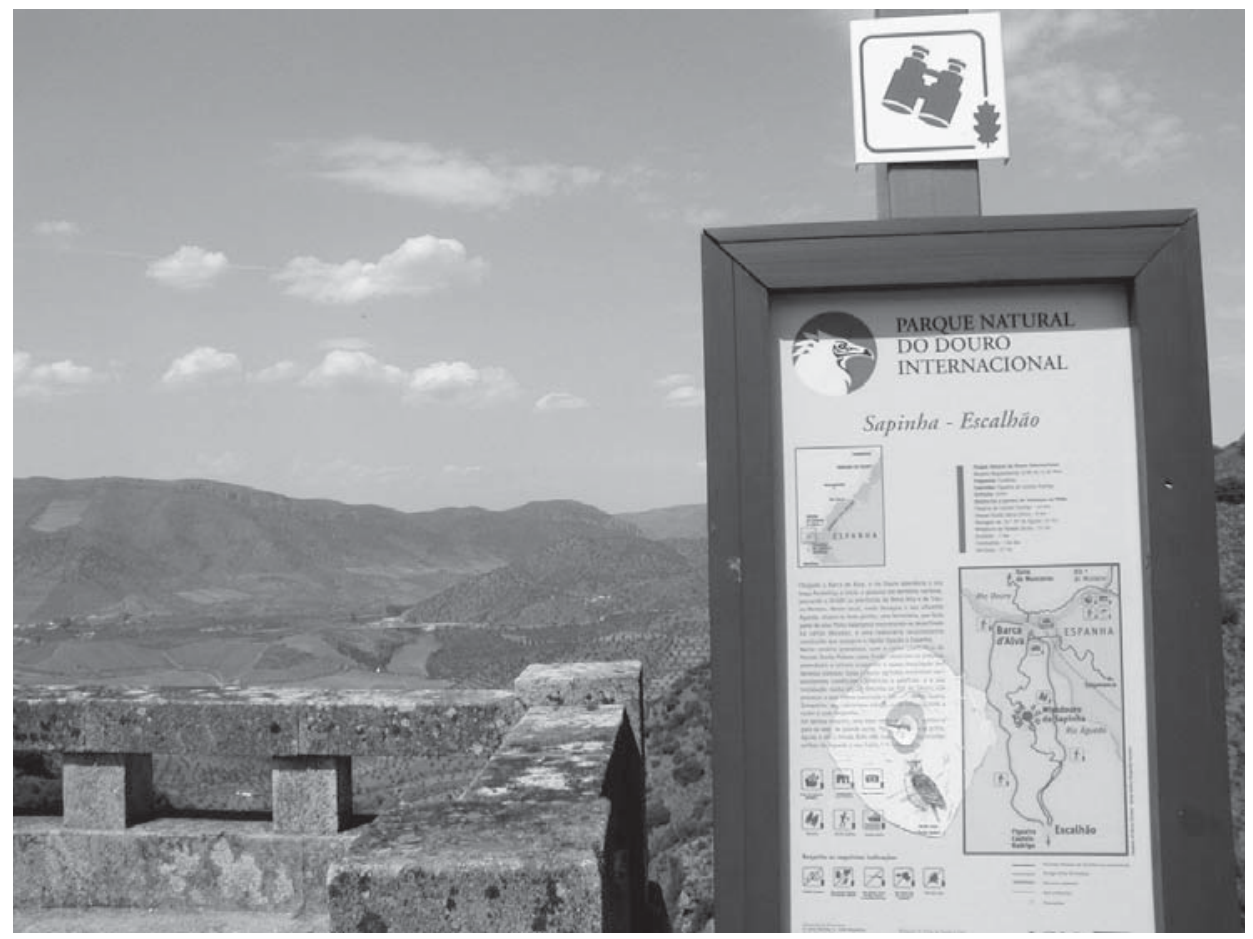

Ao sairmos do "Douro granítico" e entrarmos no "Douro do xisto" rapidamente nos apercebemos desta mudança. Na foz do Rio Águeda, em Barca de Alva, o horizonte expande-se. Surgem pequenas porções, de declive suave, onde se cultiva a vinha, a oliveira ou a amendoeira. Em outros locais as vinhas tendem a ocupar terrenos que, pela sua natureza rochosa e em declive acentuado, exigiram um intenso trabalho de preparação do solo e a sua sustentação. Na literatura são frequentes as alusões à dura tarefa que consistiu no erguer dos tradicionais socalcos e na implantação da vinha. Alguns autores chegam mesmo a apelidá-la, de forma alegórica, "uma autêntica labuta de gigantes"; «E resolveram meter o picão às fragas; reduzi-las a terrunha; amparar os seus "veios" estreitos com "socalcos" de pedra solta; e plantar sobre as escarpas, que eram sarças de fogo, os primeiros bacelos de videira» (Cortesão in Andrade, 1990: 19). A vinha, graças à fisiologia das suas raízes que procuram em profundidade nutrientes e água, adapta-se ao solo criado pelo homem após a realização da surriba. Do lado de lá da fronteira, ainda que se trate igualmente de uma paisagem vinhateira, o carácter arcaico ainda é mais acentuado, diferindo, no entanto de forma substancial na topografia (terreno plano onde se inserem pequenas parcelas, rodeadas de muros).

Nessas áreas serranas, o mesmo ocorrendo do lado português na chamada terra fria, as marcas da presença humana são esparsas e limitam-se a pequenas leiras, muitas revelando evidentes sinais de abandono, já que por vezes subsistem apenas as divisões em 
pedra. O povoamento é concentrado e os aglomerados populacionais, alguns de dimensão considerável, não deixam adivinhar a perda da vitalidade de outrora. Esse declínio pode ser facilmente observável nos testemunhos fotográficos que se apresentam. Aldeias dispersas, casas construídas em granito, pequenas leiras, já em plena área planáltica.

No vale do Douro os testemunhos da vivência humana prefiguram uma muito maior ocupação e dinâmica. Dividindo as parcelas, uma série de oliveiras, seguindo uma disposição linear, configuram autênticas formas geométricas, como se tratasse de uma tapeçaria, pelo diferente colorido da sua ramagem. Alterna o verde mais escuro da folhagem das oliveiras, com as tonalidades mais claras, sempre que a disposição da vinha acompanha as curvas de nível. Quando as vides estão dispostas no sentido principal do declive, o colorido passa a ser ainda mais diversificado, castanhos e raiados de verde e cinza escuro/ negro (solos de xisto) são a marca mais indelével da tipicidade da paisagem do Douro vinhateiro.

Se nas vertentes agricultadas já referimos que o predomínio da vinha é avassalador, a cotas mais elevadas, locais que já podemos enquadrar no Douro sub-planáltico, em vertentes de maior declive, existe uma ocupação florestal e de mato sub-atlântico em porções descontínuas e que em determinadas épocas do ano sobressaem pelo seu forte colorido. Destacam-se em Maio os tufos amarelos das giestas. Entre os fundos de vale, de feição tipicamente mediterrânea e a região planáltica existe um domínio fito-geográfico de transição. O seu carácter intermédio permite a coexistência de um estrato arbóreo em que se conjugam espécies como o carvalho roble (Quercus Robur L.), o sobreiro (Quercus Suber L.), o pinheiro bravo (PinusPinasterAiton) e no estrato arbustivo, as já citadas giestas, os tojos (UlexSpp.) o medronheiro (ArbustusWedo L.), o estêvão (CistusPopulifplius L.), etc.

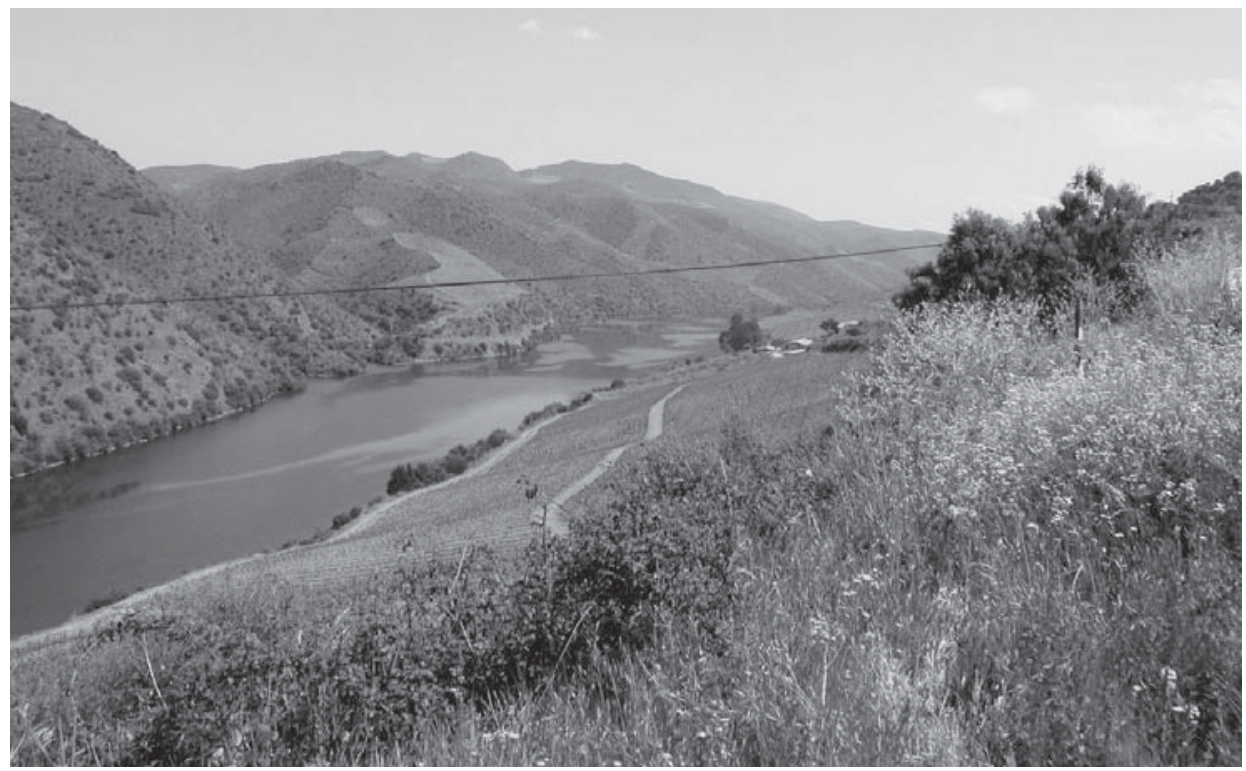


A sucessão de cumes arredondados que é regra quando nos encontramos nos terrenos mais próximos do vale do Douro, geralmente pertencentes ao complexo xisto-grauváquico, e que lhe confere uma certa regularidade paisagística, altera-se quando transitamos para os solos graníticos. Em certas áreas de contacto, os desníveis são mais bruscos, o que resulta em acentuadas quebras nos declives de alguns dos afluentes do Douro ou na presença de elevações consideráveis, lugares propícios à implantação de ermidas e miradouros. As povoações agrupam-se a meia encosta, aproveitando pequenos patamares virados a norte, já que os terrenos mais solarengos são para as vides.

\section{O TURISMO NA REGIÃO}

O aproveitamento da região duriense para fins turísticos e de lazer não é um facto novo. Basta lembrar as tradicionais deslocações estivais, e principalmente por altura das vindimas, dos proprietários não residentes, em direção às quintas, algo que ainda se mantém na atualidade. A literatura romântica do século XIX atesta essa tradição, sendo numerosos aqueles que, essencialmente por via ferroviária, se deslocavam para estadias mais ou menos demoradas na região, uns obedecendo a prescrições médicas, outros para acompanhar os labores vitícolas da fase da colheita.

Tratava-se no entanto de um quantitativo que não estava totalmente relacionado com o fenómeno turístico, pois alguns dos indivíduos viriam desempenhar uma atividade da qual recolheriam proveitos monetários, como os proprietários das quintas. $\mathrm{O}$ número daqueles que podiam usufruir das formas clássicas de alojamento em hotéis, pensões e similares, seria possivelmente reduzido, devido ao fraco desenvolvimento da atividade turística nesta região do país, assim como na generalidade do interior de Portugal.

As difíceis deslocações por estrada contribuíram para a manutenção dessa situação durante várias décadas, não constituindo o Douro um destino preferencial no quadro das regiões turísticas do país. O grande incremento do fluxo turístico dos anos 60 do século XX beneficiou quase exclusivamente as áreas balneares do Algarve, a Região de LisboaSintra e a ilha da Madeira.

Retomando a análise do que ocorria no Douro, e se nos reportarmos a alguns dos estudos que se debruçaram sobre as potencialidades turísticas desta região, assim como da generalidade das áreas rurais do interior, no período cronológico compreendido entre meados da década de 80 e meados da década de 90 do século XX (Cravidão e Cunha, 1993: 85-91), deduz-se que as ofertas de alojamento eram reduzidas e pouco diversificadas. Compreende-se portanto que os termos usados nessas avaliações fossem reveladores de uma débil capacidade de acolhimento turístico. Os autores ou instituições utilizavam expressões como "deficiente capacidade hoteleira", "reduzida expressividade em termos de número de camas" e chamavam a atenção para o pequeno número de unidades com classificação igual ou superior a quatro estrelas.

Nos últimos anos, a situação, ainda que de forma muito gradual, tem-se alterado, pois passou a ser crescente a procura por parte daqueles indivíduos que começam a ma- 
nifestar um certo cansaço relativamente às formas de turismo de massas do modelo "sol e praia". Foi evidente a melhoria e a diversificação das condições de acesso à região do Douro, nomeadamente com a introdução do turismo fluvial, a capacidade de alojamento ainda que mantendo-se deficitária, quer em termos quantitativos, quer qualitativos, tem melhorado, também fruto de uma intervenção estratégica de promoção da região sob o ponto de vista turístico (Fontes, 2000: 109-124).

O cruzeiro por barco constitui um dos meios de transporte mais aprazíveis para quem se desloca a esta área do interior norte do país, pois sem dúvida que o canal fluvial é o meio por excelência para se poder contemplar as imponentes fragas e deslumbrantes vertentes agricultadas. Trata-se de uma atividade ainda relativamente recente, uma vez que o primeiro cruzeiro entre o Porto e Peso da Régua ocorreu em 19 de Outubro de 1986 e a primeira viagem até Barca de Alva, apenas no ano de 1990, sendo o Douro o único rio português que oferece esta possibilidade, na totalidade do seu percurso em território nacional.

Para além da intervenção do Estado Português, como entidade responsável pela edificação das estruturas relacionadas com a navegação, têm vindo a crescer os investimentos privados nas empresas de navegação turística fluvial, surgiram novas unidades hoteleiras e restaurantes. Basta citar que atualmente o número de unidades de cruzeiro turístico no Douro é já de 52 embarcações.

Hoje a quase totalidade estabelece ligação com outras empresas, para a prestação dos serviços contidos nos "pacotes" das viagens. Para o alojamento recorrem a hotéis e casas de turismo rural; para as provas de vinhos, às cooperativas e quintas. Recentemente, uma das empresas de cruzeiros fluviais passou também a explorar unidades hoteleiras sediadas na região demarcada, e inclusivamente diversificou a sua atividade, promovendo viagens de helicóptero.

A explicação para este facto não se resume apenas às iniciativas levadas a cabo pelas empresas de turismo fluvial. Se a evolução foi inegavelmente fruto do sucesso empreendedor dos operadores dos cruzeiros, não deixou de ser concomitante com a evolução processada nas condições de acolhimento. Esta evidência necessita no entanto de ser matizada, avaliando-se igualmente o que tem sido implementado neste território de fronteira sob o ponto de vista do planeamento territorial e quais as virtualidades e limitações em causa sob o ponto de vista dos recursos existentes. É o que tentaremos expor, de forma breve no próximo capítulo.

\section{RECURSOS E EXPERIÊNCIAS DE COOPERAÇÃO}

Em síntese, a região fronteiriça definida pelo rio Douro, no seu troço internacional, acumula uma série de particularidades:

- Define uma fronteira entre duas regiões de países distintos, que por razões históricas só muito recentemente começam a cooperar politicamente (Região Norte de Portugal e Castela-Leão - Espanha). 
- Constitui uma fronteira natural de difícil transposição e excêntrica às principais vias de comunicação peninsulares (um vale profundamente encaixado).

- Apresenta alguns dos valores mais baixos de densidade populacional de Portugal e de Espanha, inclusivamente abaixo do limiar mínimo definido pela União Europeia para as áreas socialmente deprimidas.

- A economia de um lado e do outro da fronteira baseia-se essencialmente na agricultura, o que, aliado ao problema demográfico, condiciona o equilíbrio precário da relação entre as atividades humanas e a natureza.

- Apesar de algumas das anteriores características serem negativas, tem sido crescente o número de experiências relacionadas com o turismo e que se traduzem em casos de sucesso na cooperação transfronteiriça.

Desde meados da década de 90, uma série de instituições públicas e privadas portuguesas e espanholas têm coordenado esforços no sentido de potenciar novas formas de valorização regional e desenvolvimento turístico, tendo como espaço de actuação a região fluvial do Douro. Para facilitar a leitura, optamos por sintetizá-las em 4 áreas temáticas:

\section{VITICULTURA}

Inegavelmente um dos recursos mais decisivos, quer para o desenvolvimento do território em questão, já que é a base da economia local, pelo menos do lado português, quer como recurso paisagístico, logo, decisivo como factor de atracção turística. Aqui, cumpre destacar a classificação do Douro como Património Mundial da Unesco. Na vertente económica, as regiões vitícolas do Douro/Duero têm-se afirmado não só pelo reforço do seu prestígio, quer por intermédio dos seus vinhos de maior projecção, quer pela aposta em termos de qualidade e marketing dos vinhos menos cotados. A par desta dinâmica as rotas ligadas ao enoturismo, quer na Região Demarcada do Douro, quer nas regiões vitícolas do Duero, têm vindo a incrementar a sua importância.

\section{ARQUITECTURA E MUSEUS}

Neste campo cumpre destacar as iniciativas transfronteiriças de valorização do rico património histórico das cidades amuralhadas e a iniciativa das aldeias históricas, do lado português. A zona de fronteira volta a ser igualmente motivo de interesse para um nicho turístico de âmbito cultural ainda mais específico, que se traduz na promoção das aldeias comunitárias. Não deve ainda ser esquecido o reconhecimento da especificidade das arquiteturas rurais tradicionais, quer na vertente da habitação (aspetos estéticos), quer no da arquitetura de produção (aspetos funcionais).

\section{PARQUES NATURAIS}

Outra das valências de maior projeção e reconhecimento é a dos recursos naturais, principalmente após a constituição de dois parques com carácter transfronteiriço de um lado e de outro da fronteira, na área do Douro Internacional. 


\section{ETNOGRAFIA}

Região com determinadas idiossincrasias no campo do "Folclore": os "Pauliteiros de Miranda" e das línguas locais (Mirandês e dialetos do contrabando).

Todas estas temáticas têm-se materializado em diferentes convénios, acordos ou parcerias, de que são exemplo os estabelecidos entre associações empresariais, por exemplo por meio da participação em feiras; o projeto de fortificações de fronteira (Consórcio transfronteiriço de cidades amuralhadas); acordos de articulação universitária; dinâmicas de interpenetração económica, a exemplo da do corredor Aveiro - Ciudad Rodrigo; o Parque do Douro Internacional/Arribes; o projeto Terra Douro/Duero região fluvial, promovendo a navegabilidade do Douro; o estabelecimento de um guia ecológico do Douro; ou ainda, no campo dos sistemas de informação territorial, o observatório de desenvolvimento espacial Duero/Douro.

Dos modelos de aproveitamento turístico pode-se destacar alguns mais consolidados e outros que ainda estão numa fase inicial de desenvolvimento:

a) Natureza

- "Turismo ativo" (percursos em BTT, montanhismo; passeios pedestres...); Percursos de observação no Parque Natural do Douro Internacional

b) Viticultura

- Rota do vinho do Porto (enoturismo); Agroturismo (Turismo espaço rural)

c) Cultura popular

- Festas e romarias; Feiras e mostras de artesanato; Associativismo cultural

d) Cultura erudita

- Encontros "Casa de Mateus"; Bienal da Prata; Rotas culturais (Medieval...)

e) Museologia

- Museu de Lamego; Museu do Vinho do Porto- Régua; Museu de Foz-Côa; Museu do Ferro (Torre de Moncorvo)

f) Outros

- Congressos, Convenções; Encontros temáticos (Automóveis antigos...)

- "Amendoeiras em flor"; Estágios desportivos (Atividades fluviais)

- Rotas de arquitetura popular e etnografia

- Centros de interpretação: locais, nacionais e transfronteiriços

\section{CONCLUSÃO}

Após a passagem para o regime democrático nos dois países ibéricos, deu-se início à cooperação entre os dois estados. Durante uma primeira fase, de adaptação, foi importante a mudança das políticas de organização territorial internas - poderes regionais em Espanha e reforço do poder dos municípios em Portugal. Após a integração europeia, com o surgimento do programa INTERREG, após os anos 90, surgem os primeiros protocolos entre Norte e Centro de Portugal e a Comunidade de Castela e León e a 
integração de instituições como a Associação dos Municípios Ribeirinhos do Douro, ou ainda, a criação da Fundação Afonso Henriques. Daí decorreram os primeiros estudos, seminários e projetos de cooperação transfronteiriça sobre uma das mais emblemáticas paisagens vitícolas, classificada Património Mundial, com grande potencial cultural e ambiental e forte potencial de aproveitamento turístico, já que navegável ao longo de 200 quilómetros.

O que se propõe é, recorrendo à experiência das estruturas existentes, conceber um modelo de desenvolvimento turístico integrado e transfronteiriço assente numa estrutura de coordenação única. Numa época de recursos financeiros escassos, há que fazer valer e maximizar as boas práticas e exemplos de sucesso de uma região de inegável valor económico, paisagístico e sociocultural.

\section{BIBLIOGRAFIA}

Alvarez Perla, José Maria (1999): “El Proyecto Terra/Douro Región Fluvial, una Experiencia de Cooperación Castilla y León/Norte de Portugal” in Seminário Estratégias de Valorização de uma Paisagem: o Vale do Douro, S.L., S. E., pp. 45-49.

Caballero Arencibia, Agustín et al (coord.) (2007): Frontera y Desarrollo: Estudio del Espacio de Frontera Salamanca, Tras-os-Montes y Alto Duero, Salamanca, Diputación de Salamanca.

Cravidão, Fernanda e Cunha, João (1993): "Ambiente e práticas turísticas em Portugal”,Inforgeo - Revista da Associação Portuguesa de Geógrafos, 6: 85-91.

Cortesão, Jaime in Andrade, Eugénio de (org.) (1990): Canção do mais alto rio: antologialiterária do Douro, Porto, Edições ASA.

Fontes, António (2000): “O desenvolvimento turístico no vale do Douro: um destino em fase de afirmação, uma rede institucional em discussão" in Desenvolvimento e Ruralidades no Espaço Europeu-Actas do VIII Encontro Nacional da APDR,, Vol. I, Coimbra, Associação Portuguesa para o Desenvolvimento Regional.

Junta de Castilla y León (2007): Aprovechamiento de los Recursos Naturales Transfronterizos como Potencial de Desarrollo, Valladolid, Junta de Castilla León, Consejeria de Economia y Empleo.

Lopez Trigal, Lorenzo (2000): “El Nuevo Marco Territorial de la Región del Duero/Douro", Revista População e Sociedade, 6: 293-300.

Martins, Helder Tiago (2008): Caracterização Urbanística e Arquitectónica de uma Vila Rural Transmontana: Torre de Moncorvo, Porto, Universidade Lusíada, Faculdade de Arquitectura e Artes (dissertação de Mestrado em Arquitectura).

Miguelez Pariente, Aránzazu (2000): “Los Ejes de Cooperación entre Castilla y León y las Regiones Norte e Centro de Portugal: Resultados Obtenidos” in Carrera Hernandéz, F. Jesús (comp.) - Cooperación Transfronteiriza: Castilla y León y Portugal, Madrid, Centro de Documentación Europea, Universidad de Salamanca, Editorial Tecnos, pp. 15-34. 
Moreno, Renato (2008): Um Percurso pela Arquitectura do Vinho: Região Demarcada do Douro, Porto, Universidade Lusíada, Faculdade de Arquitectura e Artes (dissertação de Mestrado em Arquitectura).

Natario, Maria Manuela Santos (2003): “A Proximidade e a Competitividade: um Pré-Estudo à Competitividade na Raia Central Ibérica" in Nova Economia e Desenvolvimento Regional: Actas do IX Encontro Nacional da APDR, S.L., S. E., pp. 1433-1455.

Pereira, Flávio (2007): Alfândega da Fé: Crescimento e Desenvolvimento, Porto, Universidade Lusíada, Faculdade de Arquitectura e Artes (dissertação de Mestrado em Arquitectura).

Programa Terra Douro/Duero (2000): Programa Terra: Projecto Douro, Região Fluvial. Relatório Final: Balanço e Perspectivas do Ordenamento do Território na Região Fluvial do Duero/Douro, S. L., Associação Ibérica de Municípios Ribeirinhos do Douro.

Reigado, Felisberto Marques (2000): “Atividades Emergentes e Recentralização da Raia Central Ibérica” in CARRERA HERNANDÉZ, F. Jesús (comp.) - CooperaciónTransfronteiriza: Castilla y León y Portugal, Madrid, Centro de DocumentaciónEuropea, Universidad de Salamanca, Editorial Tecnos, pp. 95-118.

Sousa, Fernando de (2000): “As relações do Norte de Portugal com a Região de Castela e Leão”, Revista População e Sociedade, 6: 301-322.

\section{REFERÊNCIAS DA INTERNET}

Medeiros, Eduardo. A Cooperação Transfronteiriça na Raia Ibérica: Uma síntese geográfica dos impactes territoriais do INTERREG-A, Universidade de Lisboa, Centro de Estudos Geográficos, Núcleo de Investigação Estratégias e PolíticasTerritoriais (NEST), 2009. [referência de 1 de Julho de 2010].

Em: <http://www.ccmar.ualg.pt/gostodofrio/ct/pub_ceg_em.pdf $>$.

Junta de Castilla y León; CCDRN. Observatorio Territorial Transfronterizo para la Definición y Evaluación de Estrategias de Desarrollo Sostenible y Ordenación del Territorio en la Región del Duero/Douro, Proyecto:“Territorio Duero/Douro”. Documento final de información y difusión, 2008. [referencia de 1 de Julho de 2010]. Em: <http://www.sitcyl.jcyl.es/sitcyl/recursos/pdf/otros/TerritorioDueroDouro_InterregIIIA.pdf $>$.

Organismo Autónomo de Empleo y Desarrollo Rural. Análisis Territorial e Inventario de Recursos de la Raya Hispano-Lusa: Comarca de Ciudad Rodrigo y Tierras de Riba-Côa. Diputación Provincial de Salamanca, 2006. [referencia de 1 de Julho de 2010]. Em:

$<$ http://www.jcyl.es/web/jcyl/pr/es/NORCYL/Page/NorcylPlantillaSinHijos/12045 55094146/____?asm=jcyl $>$.

Departamento de Sociología y Comunicación de la Universidad de Salamanca; Departamento de Economia, Sociologia e Gestão da Universidade de Tras-os-Montes e Alto Douro. Estudio Prospectivo para el Desarrollo Transfronterizo. Informe que 
se presenta al Organismo Autónomo de Empleo y Desarrollo Rural de la Excma. Diputación Provincial de Salamanca, 2007.[referencia de 1 de Julho de 2010]. Em: <http://www.jcyl.es/web/jcyl/pr/es/NORCYL/Page/NorcylPlantillaSinHijos/12004 92297371/__ _ ?asm=jcyl>.

Departamento de Sociología y Comunicación de la Universidad de Salamanca; Departamento de Economia, Sociologia e Gestão da Universidade de Tras-os-Montes e Alto Douro. Frontera y Desarrollo: Estudio del Espacio de Frontera Salamanca - Trasos-Montes y Alto Duero. Organismo Autónomo de Empleo y Desarrollo Rural de la Excma. Diputación Provincial de Salamanca, 2007.[referencia de 1 de Julho de 2010]. Em:

<http://www.jcyl.es/web/jcyl/pr/es/NORCYL/Page/NorcylPlantillaSinHijos/12004 92297371/____?asm=jcyl>. 